\title{
Pronunciamiento institucional del neoliberalismo chileno: análisis del Acuerdo Nacional por la Paz y la Nueva Constitución
}

\author{
Institutional pronouncement of Chilean neoliberalism: \\ analysis of the National Peace Agreement and the New \\ Constitution
}

Pronunciamento institucional do neoliberalismo chileno:
análise do Acordo Nacional pela Paz e pela Nova Constituição

Emmanuel Farías Carrión*

\begin{abstract}
RESUMEN
Desde el 18 de octubre de 2019, Chile vive una crisis institucional

que ha sido identificada debido al espíritu subsidiario que existe en la institucionalidad chilena. Esto significa que el sistema político experimenta por primera vez la posibilidad de lograr una Constitución con una participación amplia de la sociedad civil, ¿esto es así? Este argumento analizará el evento político que nos lleva a este momento constituyente: el Acuerdo por la Paz y la nueva Constitución. Se realizará una analogía entre el acuerdo Nacional para la transición a la plena democracia, pactado en la dictadura de Pinochet, y el actual acuerdo nacional por la paz y la nueva Constitución, que aparece en la democracia pospinochetista. Ambos acuerdos se caracterizan por compartir ciertas analogías: anular al pueblo como agente político y continuar con el programa de modernidad, el cual ha traído como consecuencia la institucionalización de la democracia liberal. Luego, se utilizarán algunas posiciones teóricas para poder realizar un análisis desde la sociología política y finalmente examinar si en este acuerdo existe una real pretensión democratizadora.
\end{abstract}

Palabras clave: Acuerdo

Nacional por la

Paz y la Nueva

Constitución, modo de significación imperfecta, vanguardias, $2 / 3$.

Sociólogo, Universidad Católica Silva Henríquez. Rennes, Francia. E-mail: emmanuel.fariascarrion@gmail.com 


\begin{abstract}
Since October 18, 2019, Chile experienced an institutional crisis identified through Chilean institutions' subsidiary spirit. This means that the political system is experiencing the possibility of achieving a Constitution with broad civil society participation for the first time. This argument will analyze the political event that brings us to this constituent moment: the peace agreement and the new Constitution. An analogy will be made between the national accord for the transition to full democracy, agreed upon during the Pinochet dictatorship, and the current national agreement for peace and the new Constitution, which appears in the post-Pinochet democracy. Both agreements are characterized by sharing certain analogies: to annul the people as political agents and continue with the modernity program, which has brought about the institutionalization of liberal democracy. Some theoretical positions will then be used to analyze political sociology and examine if there is a real democratizing pretension in this agreement.
\end{abstract}

\section{RESUMO}

O Chile vive, desde 18 de outubro de 2019, uma crise institucional identificada devido ao espírito subsidiário existente na institucionalidade chilena. Isto significa que o sistema político experimenta pela primeira vez a possibilidade de elaborar uma constituição com ampla participação da sociedade civil, não é? Este argumento analisará o evento político que nos leva a este momento constituinte: o acordo pela paz e pela nova constituição. Será feita uma analogia entre o acordo nacional de transição para a democracia plena, firmado durante a ditadura de Pinochet, e o atual acordo nacional pela paz e pela nova constituição, que aparece na democracia pós-Pinochet. Ambos os acordos se caracterizam pelo compartilhamento de certas analogias: anular o povo como agente político e continuar com o programa de modernidade, que trouxe a institucionalização da democracia liberal. Logo, algumas posições teóricas serão usadas para fazer uma análise da sociologia política e finalmente para examinar se neste acordo existe uma verdadeira pretensão democratizadora.
Keywords:

National

Agreement for

Peace and the

New Constitution, mode of imperfect meaning, vanguard, $2 / 3$.

Palavras-chave: Acordo Nacional pela Paz e pela Nova Constituição, modo de significação imperfeita, vanguardas, $2 / 3$. 


\section{Introducción}

Desde el 18 de octubre de 2019, Chile comenzó a vivir una crisis no recordada por políticos e intelectuales desde el regreso de la democracia -posdictadura de Pinochet. Diremos, en términos generales, que es una revuelta que obligó al poder ejecutivo a llevar a cabo ciertas demandas que estaban cauteladas por la burguesía nacional y que desenmascaró, al mismo tiempo, a una socialdemocracia con vestiduras de izquierda y un ultraconservadurismo de aquellos autodenominados liberales, es decir, la derecha chilena y la elite política que administra el modelo pospinochetista.

Esta clase política, y en especial la derecha neoliberal, no es muy difícil de entender, es predecible en su forma de actuar; se puede intuir fácilmente cómo será una votación frente a un proyecto de ley o, en el caso que pierdan en ambas cámaras, bajo qué argumentos apelarán al Tribunal Constitucional si dicha ley no representa sus intereses, por ejemplo: la titularidad sindical que fue declarada inconstitucional, y asimismo con la creación de un Sernac con más facultades, el lucro en la educación o el aborto por tres causales. La derecha chilena y la clase política en general es antropófaga cuando unos tienen más notoriedad mediática que otros, su estructura de creencias se puede describir de manera bastante genérica y el común de la población, incluso sin saber, la conoce bien dado que la vive en el día a día. La tradición marxista entiende esto como enajenación (Pérez Soto, 2008). Entonces, podríamos decir que la derecha tradicional en Chile plasma su ideología en la carta constitucional de abierta inspiración franco-pinochetista, por lo tanto, oligarca, católica y que recurre a la moral del autoritarismo liberal hayekiano (Farías, 2019) para poder actualizarse frente al modelo de globalización desde mediados del siglo XX.

Existe literatura historiográfica sobre cómo el positivismo del siglo XIX, marcado por el liderazgo de Diego Portales (Mascareño, 2008; Moullian, 2002), continua en el tiempo mediante una tradición conservadora y autoritaria, el cual se extiende al pasado siglo con la imagen de Jaime Guzmán. Él junto a la comisión Ortúzar son quienes forjaron la arquitectura del modelo chileno y quienes con una camisa de fuerza introdujeron los cerrojos de una institucionalidad neoliberal (Atria, 2013), un modelo de desarrollo que hoy está traspasando los límites del colapso tanto política como económicamente (Mayol, 2012). 
Hasta ahora no se ha dicho nada nuevo, podríamos decir que es este el elemento contextual de la introducción.

Este artículo reconoce a Chile como la antesala del neoliberalismo mundial, el "experimento" dirían algunos. Esto es posible gracias al clásico aforismo político que dice: "Chile fue/es el laboratorio del neoliberalismo". La modernización capitalista de la sociedad chilena trae todos los delirios de la desigualdad como promoción de competencias individuales propios de la cultura liberal y, asimismo, los años noventa como el intento de algunos partidos socialdemócratas de humanizar el modelo, algo así como un "capitalismo social", es decir, de darle un rostro humano, decían algunas propuestas que con una sospechosa astucia tecnócrata gobernaban el modelo de desarrollo nacional (Concertación de Partidos por la Democracia periodo 1990-2010). Sin ningún reparo en su origen y consecuencias, Chile vivió los noventas e inicios del siglo XXI con esta herencia. Incluso la reforma constitucional de 2005 con la firma del expresidente Lagos no pudo sacar el espíritu subsidiario de la Constitución. La administración neoliberal en un contexto socialdemócrata, sumado a una serie de políticas que buscaban humanizar el proceso de modernización capitalista en Chile, trae como consecuencia el levantamiento de octubre. Por lo mismo, a continuación se realizará mediante un análisis teórico cómo algunos partidos políticos de inspiración socialdemócrata y neoliberales de tradición pinochetista (que aparentemente es lo mismo), pactan el Acuerdo por la Paz y la nueva Constitución que pretende mantener de una u otra forma la resistencia del laboratorio neoliberal.

Esta primera parte del artículo será un formato propedéutico de lo que más adelante podría ser una lectura teórica, o un intento de ella. Para esto, lo primero es comprender los rasgos políticos más elementales de una realidad próxima para asíllegar a un momento teórico-político. En otras palabras, se analizará lo que vive Chile luego del 18 de octubre de 2019 para poder desenmascarar aquello que subyace en las cuestiones escatológicas propias de la teoría política, o sea, el debate público y más aún los intereses de clases. Mediante un método documental (Barboza, 2006) este nos ayudará a analizar el debate realizado entre Fernando Atria y Carlos Pérez Soto. Ambos levantan un perfil sobre cómo comprender el concepto de pueblo, el cual será útil para interrogar el acuerdo del 15 de noviembre, y de esta forma se podrá 
hacer las analogías entre el pacto que se realizó en la dictadura militar "Acuerdo para la transición a la plena democracia" (Tagle, 1995) y el realizado en la democracia neoliberal "Acuerdo por la paz y la nueva Constitución". Es en las similitudes de ambos procesos donde reposaría la sospecha política de este texto.

Observar desde las ciencias sociales, y en especial la sociología, requiere precisar ciertas distinciones. Por un lado, existe en la tradición sociológica quienes tienen posiciones científico-descriptivas frente a aquellos que buscan formas genealogistas para la comprensión de la historia. Es por esto que la posición teórica, es decir, el modo de comprensión que enfrenta esta tesis será hibrida, en tanto ninguna de las posiciones debe ser entendida como cuestiones aisladas, sino, más bien, ambas como parte de una misma cosa. Esto nos permitirá anular cualquier tipo de reduccionismo y ayudará a no ahogarse en la moderna tradición empirista. Sus apartados estarán divididos en: (i) la práctica institucional que tiene el sistema político chileno (para efectos de este argumento: "la cocina"); (ii) la definición de pueblo a partir del debate Atria-Pérez Soto en el congreso de filosofía política de la Universidad de Chile en el año 2012; (iii) las consecuencias del acuerdo; y finalmente (iv) concluir con la necesidad de un discurso democrático amplio a la comunidad política.

\section{Primera aproximación teórica: hacia una sociología política}

Para que la lectura pueda ser teórica, se dirá que existe un movimiento pendular en ella, es decir, una distinción entre lo real y lo posible (Pérez Soto, 2008). Aquí es donde se puede encontrar la cuestión escatológica propiamente tal. Este movimiento pendular se logra mediante las operaciones temporales con las cuales convive la realidad social: pasado y/o futuro o, mejor dicho, en la distinción sociológica experiencia/expectativa (Mascareño, 2008). En las expectativas yace una mirada sobre un devenir y cómo frente a un futuro incierto y/o contingente, por cierto, enfrentamos posibilidades de riesgo que la experiencia logra estabilizar mediante normas. La norma se ha convertido en objeto de estudio de un legado importante de las ciencias sociales y jurídicas. Mediante la comprensión de la idea de cultura, aquella capaz de generar unidad, comunidades políticas, instituciones, pueblos, 
organizaciones o, como más les gusta decir a los sociólogos, cohesión social. La política en el sentido amplio de la palabra buscaría anular cualquier posición de riesgo, generando una especie de ingeniería social que produce este movimiento pendular entre lo real y lo posible. La política, justamente, lo que busca es el control de la contingencia, empero, hoy la política se convierte en la variable de riesgo, en tanto no ha podido definir una idea de comunidad y la organización de esta. Durante el último siglo, la tesis neoliberal atraviesa dicha discusión, imponiendo la noción de democracia liberal en la organización política de la sociedad y permeando la institucionalidad pública.

En el caso chileno, podemos ver cómo la subsidiariedad y los tecnócratas del Estado no son ni fueron capaces de anticipar una crisis política tal como la vivida en el octubre chileno de 2019. Es aquí donde la pretensión del Estado y la economía social de mercado fracasan en el cumplimiento de expectativas, está última asegurando la satisfacción de las personas mediante la retórica de consumo: emerge el homo economicus como principio regulador de una moral liberal (Ruiz, 2019); un principio regulador que vive una crisis de expectativas. Para el laboratorio chileno cabe la siguiente suma. Democracia liberal, Estado subsidiario y gasto social focalizado (Farías y Moreno, 2016). Entre estas tres dimensiones se ha generado una regularización de las expectativas de las personas; es cómo se pretende controlar el movimiento pendular del tiempo. Esta es la propuesta política de la derecha y la socialdemocracia neoliberal chilena: "controlar" el devenir de la historia mediante la lógica de la eficiencia y eficacia.

La eficacia y eficiencia fueron valores centrales en la racionalidad capitalista de los economistas de Chicago, quienes no lograron comprender que la historia es un campo previamente dado, de construcción intersubjetiva y contingente. La sociedad es complejidad y en ella existen operaciones que ni la economía ni la política pueden aprehenderlas. Independiente de las diferentes disposiciones morales (Mascareño, 2010), "la teoría puede relacionar contextos y proyectar posibilidades a partir del uso heurístico de la analogía y de ninguna manera probatorio necesariamente" (Pérez Soto, 2008, p.28). Por esto, la observación sobre la contingencia, a pesar de su elemento probabilístico, necesita de un examen político y es justamente aquí cuando comprendemos que el neoliberalismo ha fallado en el cumplimiento 
de las expectativas y será este el fundamento del presente artículo, el cual obliga al desarrollo de un argumento desde la sociología política, por lo que convierte esto en una tesis política.

Para lograr una antesala teórica o propedéutica, correspondería invocar al arte de la prognosis y cómo esta nos permite anteponer un escenario al cual podamos observar. Koselleck (2003) escribió con una claridad única que

el estatuto de lo futuro no se corresponde entonces plenamente con el estatuto de lo pasado. Lo pasado está contenido en nuestra experiencia y es verificable empíricamente. Lo futuro escapa por principio a nuestra experiencia y, en consecuencia, no es verificable empíricamente. Sin embargo, hay predicciones que, con mayor o menor plausibilidad, pueden ser transpuestas de la experiencia a la expectativa. (p.75).

ciertamente y esto, para algunos metodólogos, puede ser inextricable en tanto no reconocería la dimensión más "empírica" de la realidad social, pudiendo sonar pecaminoso o abstracto, como si esto fuera un problema. Chernilo (en Archer, 2009) en el prólogo de Teoría Social Realista. El enfoque morfogenético dirá:

La disciplina no puede ni debe disolverse en una empresa fundamentalmente cuantitativa; menos aún en una forma sofisticada y algo pedante de periodismo en la que el trabajo del sociólogo se reduce a preguntarles a los actores respecto de sus representaciones sobre cualquier tema. (p. 14).

Es necesaria la distinción entre lo real y lo posible, aquello que atiende la teoría es justamente esta segunda parte, es decir, lo posible. Por lo tanto, describiremos de manera no muy venturosa cuáles son los elementos que sostienen a la teoría para que pueda ser política.

Ya se dijo, por un lado, que existe en el movimiento pendular del tiempo la distinción experiencia/expectativa y, por otra, un aparataje político descifrado, para el caso chileno, como democracia liberal, Estado subsidiario y gasto social como elementos clave del laboratorio. Esto nos arrojará una sociedad nacional liberal -una comunidad política- altamente desconfiada (Peña, 2020), carente de sentido histórico y embriagada por la fiesta del consumo (Moullian, 2002). Este topos permitirá comprender cómo el neoliberalismo formó una idea 
liberal de pueblo y detonó un malestar político representado en el octubre de 2019.

\section{La cocina: el pacto del 15 de noviembre}

Los consensos de la institucionalidad política en contexto de crisis se convierten ya en una cuestión indispensable en la historia política del país, tal como lo vivió Chile en 1985 con el "Acuerdo nacional para la transición a la plena democracia", el cual fue suscrito por partidos de centro y derecha, excluyendo la participación de facciones de izquierda, entre ellos el partido comunista y todo el movimiento democrático popular (Ortega, 1992), o 29 años después con el "Acuerdo por la paz social y la nueva Constitución", en el gobierno de Sebastián Piñera (de aquí en adelante, el Acuerdo). Es menester hacer una descripción de cómo la elite piensa la lógica de los acuerdos políticos. En una nota publicada en El Mostrador se indica a Andrés Zaldívar hace cierta metáfora sobre estos.

Algunos se sienten más o menos informados, pero en estas cosas no todo el mundo puede estar en la cocina, ahí muchas veces está el cocinero con algunos ayudantes, pero no pueden estar todos, es imposible. (Saleh, 2017).

La receta fue la misma que en los años de dictadura: consensos entre partidos de centro y derecha, excluyendo sectores de izquierda. El 15 de noviembre del 2019 se vuelve a excluir la participación de agentes políticos clave al momento de generar un gran acuerdo democrático, nuevamente el partido comunista y ahora la mesa de la unidad social, esta última compuesta por una serie de agrupaciones sociales, políticas, culturales, sexuales, coordinadoras, federaciones, sindicatos, colegiados, movimiento de pobladores, agrupaciones de detenidos desaparecidos por la dictadura, confederaciones, fundaciones, etc., en total más de 182 organizaciones agrupadas en la misma instancia. Nuevamente la historia se repite, no todo el mundo puede estar en la cocina.

Hegel, observa en alguna parte que todos los grandes hechos y personajes de la historia universal acontecen, por así decirlo dos veces. Olvido añadir que, una vez como (gran) tragedia, y la otra, como (lamentable) farsa. (Marx, 2009, p. 37). 
Ambos hechos muestran que la lógica de los consensos continúa en el tiempo, fueron las formas en las que la alianza democrática pactó con el gremialismo en los años de dictadura al alero de Ricardo Lagos, Gabriel Valdés, Patricio Aylwin y Andrés Zaldívar, entre otros. Asimismo, los gobiernos de la Concertación de Partidos por la Democracia administraron la democracia posdictadura, y Pinochet durante todo el proceso de transición estuvo como comandante en jefe de las Fuerzas Armadas, para luego ocupar un escaño parlamentario mediante la disposición constitucional de senador designado. Si tuviéramos que caracterizar los inicios del siglo XXI, diremos tres hitos que marcaron el devenir de una institucionalidad que ya avisaba procesos de transformación. Primero, las movilizaciones estudiantiles de 2006, también llamada revolución pingüina por los medios de comunicación, las cuales pusieron sobre la mesa toda la fuerza de la subsidiariedad del gobierno, dando como respuesta el crédito con aval del Estado, lo cual intensificó un malestar que ya venía generándose en la población chilena. Segundo, el año 2011, Chile vive nuevamente la irrupción del movimiento estudiantil, obligando incluso al último gobierno de Michel Bachelet a hacer la promesa de gratuidad en su carrera presidencial. Finalmente, en 2018 Chile vive la desaparición del sistema binominal, generando que las nuevas fuerzas políticas entren al parlamento; todas ellas nacieron al calor de estas manifestaciones anteriormente mencionadas. Es así como después del 18 de octubre de 2019, la democracia chilena, con una actitud proselitista, vuelve a estabilizar las expectativas colectivas -el llamado estallido social- mediante la experiencia institucional chilena, es decir, el Acuerdo del 15 de noviembre de 2019.

Vuelve aparecer la idea central del argumento; la experiencia se proyecta al futuro; es ver cómo la experiencia de los acuerdos políticos que excluye a los sectores populares vuelve, reaparece y anula la contingencia de la sociedad nacional, rechaza la posibilidad de un acuerdo político nacional amplio y se vuelve a imponer la misma fórmula de negociación que la de los años de dictadura. Es cómo se construye la comunidad política en el laboratorio, es cómo se define la cohesión social, y más aún, es cómo se definen las instituciones del pueblo. Los consensos de la institucionalidad aparecen como una receta obligada en el sistema político chileno. Así, por ejemplo, sectores de izquierda en los años de dictadura manifestaron que la democracia que advie- 
ne será la democracia de Pinochet. Entre estos argumentos estuvo por qué colectivos, como el Movimiento Izquierda Revolucionaria, Frente Patriótico Manuel Rodríguez y Movimiento Democrático Popular, incluyendo al partido comunista, nunca aceptaron con pleno convencimiento los años venideros de una democracia evidentemente neoliberal (Rojas, 2011).

Si en los noventa se proyectó y administró una democracia neoliberal, la pregunta sería: ¿Cuál es la posibilidad de que un nuevo acuerdo con condiciones análogas a la de los años de dictadura cumpla con lo dicho el 15 de noviembre de 2019? Desde que la elite política chilena opta por un nuevo acuerdo sin la participación completa de los actores sociales y políticos movilizados, la contingencia de las sociedades nacionales -tal como lo ha vivido Chile- se proyecta con una clara intención de control institucional de la burguesía nacional. Es cuando la historia opera como un elemento cíclico y reproduce estructuras de clases; es cuando se anula la contingencia de la sociedad moderna; es cuando la estratificación de la sociedad se proyecta en el tiempo y no permite sociedades diferencialmente funcionales, diría así la teoría de sistemas sociales, por ejemplo (Chernilo y Mascareño, 2010), que es finalmente cuando se anteponen los proyectos de modernización capitalista en el Chile actual.

\section{¿El estallido social corresponde al estallido de un pueblo?}

El 15 de noviembre de 2019, la elite política en el parlamento opta por dar una vía institucional al estallido social mediante un plebiscito constitucional. En el rigor teórico de las ciencias jurídicas o sociales, esto significa volver a facultar la capacidad soberana del pueblo mediante el voto plebiscitario. Es como el soberano ejerce su poder, en la elección. Ahora, los antecedentes son varios, como los ya descritos: una cultura política evidentemente liberal, la exclusión de las facciones de izquierda y pactos a espaldas del poder soberano y legitimo del pueblo. El 15 de noviembre se convertirá en uno de los anales de la historia política del país, donde nuevamente, mediante la lógica de la exclusión y la no participación de un proceso político amplio, se neutraliza la emergencia de todos los sectores movilizados, el mayor acto democrático chileno en su historia republicana vive una paradoja pro- 
pia del despotismo ilustrado, es decir, todo para el pueblo, pero sin el pueblo.

Para las ciencias sociales, políticas y jurídicas "pueblo" es lo que aparece en el relato general de la historia política moderna. Se escribieron ideales políticos tales como "la soberanía reside esencialmente en la nación y se ejerce por el pueblo", "la ley es la voluntad del soberano y el soberano es el pueblo" y "otros invocan himnos en tonos revolucionarios como el pueblo unido jamás será vencido". Pero, ¿qué es el pueblo? ¿Fue el pueblo el que se levantó el 18 de octubre de 2019? o ¿fue el pueblo el que entre el 18 de octubre y el 6 de diciembre de 2019 sufrió de 28.000 detenciones, en muchos casos arbitrarias según Naciones Unidas? (Oficina del Alto Comisionado de las Naciones Unidas para los Derechos Humanos, 2019). El mismo órgano indica que entre las mismas fechas existieron 113 casos de tortura, 24 casos de violencia sexual, 26 muertes asociadas a contextos de protestas, 4.903 personas heridas hasta el 10 de diciembre del mismo año y 350 personas con mutilaciones oculares por el uso indiscriminado de armamento por parte de los agentes del Estado. ¿Esa represión fue contra el pueblo?

La necesidad de profundizar en la idea de pueblo esta dada por dos cosas: primero, levantar una discusión política sobre cuáles son las visiones que existen en Chile sobre esta conceptualización política y, segundo generar un modo de comprensión teórica sobre el Acuerdo. De esta forma, podremos interrogar en detalle a qué se enfrenta el proceso constituyente con el quorum legislativo que se acordó dicha noche. Entonces, ¿qué es el pueblo? La respuesta evidentemente tiene mamotretos de historia política universal, pero como el siguiente documento está preocupado de la prognosis que existe desde la teoría y la política en el caso chileno, se utilizará para esta pregunta un debate entre Carlos Pérez Soto y Fernando Atria ${ }^{2}$ realizado el año 2009 y luego el 2012.

2 Ambos expusieron sus argumentos en el "V Ciclo de filosofía política" (primero en 2009 y luego en 2012), organizado por los estudiantes de derecho de la Universidad de Chile sobre aspectos generales de cómo reconocer el papel de la institucionalidad (como Estado de derecho) en un régimen neoliberal y la respuesta de las fuerzas políticas que están desde la vereda de la oposición. Para Atria, pueblo será comprendido desde el "modo de significación imperfecta", mientras que, para Pérez Soto, mediante la "revolución de masas o pedagogía revolucionaria". Para dicha discusión, el profesor Pérez Soto utilizó dos argumentos que se pueden encontrar en: Proposición de un marxismo hegeliano (para este artículo se revisó la primera edición del año 2008) y en La violencia del derecho y el derecho a la violencia (2012); mientras que el profesor Atria presentó: 


\section{El debate Atria-Pérez Soto sobre las instituciones del pueblo}

Entre ambas posiciones existen encuentros, desencuentros y en algunos casos (con bastante esfuerzo) acuerdos. El debate político que vive hoy Chile necesita de ciertas claridades para poder comprender cuál es el contexto de esta disputa política; en este caso, desde la concepción de pueblo. Primero, Atria comprende que en el pueblo existe un incumplimiento de la promesa de la ilustración. El pueblo nace como una inspiración burguesa propia de la revolución de finales del siglo XVIII, es una proyección política de un sujeto que emerge con el fin de marcar la separación de los poderes del Estado e imponer la idea de libertad como máximo regulador de la esfera política. Esta idea de pueblo es en sí misma una contradicción producto de la influencia del liberalismo que aparece por toda la tradición moderna y transforma la decisión pública, emitida mediante el voto, en una decisión privada (Atria, 2009) así es como se institucionaliza la voluntad general y comienzan aparecer los primeros indicios del liberalismo moderno que envuelve la idea de pueblo. Por esto es que pensar que la ley es la voluntad del pueblo sería una ingenuidad. Mediante este agente liberal es cómo se comienza a definir el espíritu del Estado de derecho. En su emergencia, existiría una solapada pretensión de control mediante el principio de voluntad general, o sea, el pueblo y su institucionalización. Al comenzar a interrogar lo sucedido entre el 18 de octubre y el 15 de noviembre, se puede divisar justamente esto. La necesidad de unos por cooptar la expresión política de la revuelta, llevarla a su institucionalización. La crítica al acuerdo no debe ser en lo absoluto entendido como un capricho político, es más bien un hecho que el operar de los sistemas políticos tiene una forma. El Acuerdo por ejemplo fue autoconvocado entre presidentes de algunos partidos. Dicho acuerdo nunca pasó en algún momento por alguna comisión del parlamento, anulando los principios de Estado de derecho.

Es ingenuo pensar que las instituciones del Estado de derecho, tal como ellas realmente existen, están a la altura de sus propias pro-

Viviendo bajos ideas muertas: la ley y la voluntad del pueblo (2009) y La idea de teología política (2012). Por esto es que la idea de pueblo para este ensayo será la síntesis de dicha discusión. 
mesas y por eso son exitosas en asegurar que los poderes fácticos, esos poderes que no descansan en ni requieren legitimación, sólo actuarán cuando su acción sea en el interés de todos. El ingenuo que ha adquirido conciencia de su ingenuidad entonces se vuelve cínico: es que la promesa del Estado de derecho es entonces enteramente falsa, sólo un engaño [las cursivas son mías].

El argumento anterior pretende mostrar que la postura ingenua del que cree que porque el Estado de derecho promete domesticar los poderes fácticos lo hace plenamente comparte el mismo error del que cree que porque no es capaz de domesticarlos enteramente es un engaño: ambos ignoran el hecho de que las instituciones existe en un mundo alienado (o de pecado), y son maneras de hacer probable formas de vida que sin ellas serían radicalmente improbables. Es improbable que quien tiene fácticamente poder lo use en pro del interés general; lo probable es que lo use para dominar al otro [las cursivas son mías]. Como las instituciones existen para hacer probable lo que es improbable, la misma razón que explica su existencia en primer lugar implica que no tendrán éxito plenamente. $\mathrm{Ni}$ el cínico ni el ingenuo pueden entender qué son y cuál es el sentido de las instituciones, y por eso no pueden entender las instituciones [las cursivas son mías]. (Atria, 2012, p. 121).

Si la voluntad del pueblo es una voluntad general representada en leyes que constituyen el Estado de derecho, ¿cuál es la probabilidad concreta que una multiplicidad de voluntades se convierta en una voluntad general? Es aquí donde se consuma el poder político como promesa de cumplimiento institucional, una promesa que ha sido puesta en cuestión en el siguiente debate. Ahora, vivimos en un mundo institucionalizado; no es el objetivo de esta tesis decir lo contrario. Hasta hoy, lo que se conoce es que en ese mundo institucionalizado existe una disputa política que pretende normativizar nuestras formas de vida. Para el caso especifico del Acuerdo, encontramos justamente la justificación de Atria sobre el rol de las instituciones -"lo probable es que lo use para dominar al otro" (Atria, 2012, p.121)- si el proceso de nueva Constitución como expresión institucional tiene la expectativa de la hoja en blanco. Lo cierto es que el quorum para la aprobación de las normas deberá ser de 2/3, según se indicó el 15 de noviembre, entonces, diremos que la multiplicidad de voluntades representadas 
en el pueblo puede sufrir el veto de un tercio más uno de quienes estarán participando en el proceso constituyente si sus intereses no se representan, lo que imposibilita la creación de una nueva voluntad general. Evidentemente, este error conlleva una ingenuidad por parte de los sectores de centro izquierda que participaron en el acuerdo. Todo esto pone en riesgo la condición de expectativas que se genera entorno al proceso dada la experiencia institucional que tiene Chile con los acuerdos políticos.

Todo esto hace necesario profundizar el debate político que se genera desde la academia. Asimismo, Carlos Pérez Soto comprenderá a "pueblo", por su influencia del siglo XIX, como una idea moderna gracias a Hegel. Para Pérez Soto, esta idea estaría atravesada por la tragedia, en esta existiría un núcleo hegemónico donde la burguesía pretende generar una condición material de explotación que nos expone a un estado de sufrimiento: quien explota sería el capitalista y quien es explotado sería el pueblo. Luego, Pérez Soto construye un aparato político como sujeto revolucionario inspirado por el proletario en Marx, del mismo modo que una nueva proyección revolucionaria que se representa hoy en la violencia de masas que, dicho sea de paso, se ha convertido en un objeto de sospecha revolucionaria por la duda que han generado los fracasos de la izquierda clásica que desembocó en totalitarismos y dictaduras. Aquí aparece el sujeto y la violencia revolucionarios como una obligación moral y política y no como una continuación de los fracasos de los socialismos reales.

Como ya se dijo, el pueblo se comprenderá como una relación de clases a partir del principio de explotación capitalista, donde la utilización de los medios de producción genera el enriquecimiento de unos y la miseria de otros. Para Pérez Soto, la obtención de la institucionalidad podrá generar un paso para un horizonte comunista que traspasará la condición de miseria o enajenamiento. En ese horizonte, se proyecta una sociedad sin lucha de clases y, por tanto, sin desigualdades, tal como ya lo viene diciendo el marxismo desde hace más de 150 años. Sin embargo, en el horizonte comunista, la utilización de las instituciones (como instrumentos burgueses) ya no serán una necesidad.

Una sociedad sin instituciones institucionalizadas. En que haya intercambio pero no mercado, gobierno pero no estado, familias pero 
no matrimonio, rito pero no rituales, orden pero no leyes. Esa es la sociedad comunista. (Pérez Soto, 2008, p. 91)

Lo que generan estas posiciones es la comprensión teórica detrás del aparato institucional y nos permiten, como se dice inicialmente, lograr un examen político. El problema estaría en que la tradición moderna y la democracia burguesa para Pérez Soto (2012) provocaría una institucionalización de la paz como "dictadura democrática" (p. 83), la cual sería mucho más eficiente al momento de consolidar el dominio de su alternativa totalitaria, mientras que para Atria existiría una fuerza reguladora de nuestras formas de vida, aparecería la pregunta: ¿Cómo mantener la tensión pese a la brutal fuerza niveladora de la normalidad? (Atria, 2009). Esto debido a que hoy vivimos bajo el imperio de ideas muertas como una fuerza niveladora, es decir, ideas que son operativas pero que son ininteligibles (Atria, 2009). Lo que logra esta ininteligibilidad es apartar a los agentes políticos no institucionales de la participación en cuestiones políticas o públicas. En consecuencia, se hace necesario que el control institucional se logre mediante el ejercicio de presión que se pueda generar desde los distintos territorios con el fin de lograr mayores niveles de profundización democrática. Esta forma anula la contradicción de pueblo como aquello que ofrece la promesa de la modernidad frente a los que realmente vivimos: "sufrimiento" en términos de Pérez Soto (2008, p. 73), o enajenación, experiencia existencial en déficit, según Atria. Como sea, ambas son contradicciones de forma de vida, en la cual se promete lo que no se puede dar. Este es el primer examen teórico que se hace del Acuerdo.

Ahora, le pregunta, para efectos de este argumento, será: ¿Cómo este debate contribuye en términos teóricos a lo que vivió Chile?, ¿cómo puede ser entendido el Acuerdo? En líneas anteriores ya aparecieron algunos rasgos teóricos que nos pueden ayudar a comprender el problema histórico que se enfrenta. Primero, una elite política que coapta la revuelta a través de un discurso por la paz; segundo, una tradición de institucionalidades que ha sido heredada en el tiempo con un origen conservador (desde el Estado portaliano); y, tercero, un pueblo que expresa su descontento en las calles sin ningún principio de representación. Para profundizar más esto último, se utilizará la tesis de teología política de Fernando Atria del mismo debate. Atria desa- 
rrolla teología política como una forma con dos partes. La primera es mediante un modo de significación imperfecta y la otra, una significación perfecta. Ambos modos rompen con la arbitrariedad que puede existir al pensar en un conflicto político y, en este caso, cuál es el papel que ocupa el acuerdo en la historia política de Chile. Teología política enfrenta una primera dualidad: fe/idolatría -modo de significación perfecta o positiva-, en la que se escucha la promesa con ingenuidad y se acepta aquello que se dictamina y nos llevaría a una experiencia existencial en déficit o de sufrimiento, contra un modo de significación imperfecta: fe/atea o negativa, la cual comprende sin ingenuidad cómo en la institucionalidad se realizan promesas para la construcción de ideas muertas.

De dos hombres sin experiencia de Dios, aquél que le niega es quizás el que más cerca está de él. La religión como fuente de consuelo constituye un obstáculo para la verdadera fe; en este sentido, el ateísmo es una purificación. (Simon Weil en Atria, 2009, p. 20).

Para Atria (2012), esta sería la forma más sofisticada de comprender el discurso político; gracias al discurso teológico, existiría una analogía entre conceptos. Aquel que asume un modo de comprensión perfecta sería un infantilista, entonces, asumir el pacto del 15 de noviembre como un acuerdo democrático sería, infantilista, ingenuo o, en algunos casos, cínico.

Lo que esto quiere decir que negar la relevancia de la significación imperfecta no es un error conceptual, es un error político (o teológico). El que ignora la significación imperfecta del discurso político se ve forzado por ello a dar a sus posiciones políticas ciertos contenidos: si está a la derecha, tendrá que elegir entre conservadurismo y liberalismo; si está a la izquierda, tendrá que asumir una posición de infantilismo revolucionario. Es un error, entonces, político. $\mathrm{O}$ al menos esa es la tesis. (Atria, 2012, p. 96).

Por su parte, Pérez Soto (2012) dirá que las experiencias revolucionarias siempre han existido una vanguardia iluminada e intelectual que agencia la revolución de masas, la cual se apropia de la violencia revolucionaria:

La violencia revolucionaria debe entenderse como violencia política y masiva. Las revoluciones deben hacerlas los pueblos, no los 
milicos, ni aunque sean de izquierda. Deben hacerlas los trabajadores como conjunto, no sus vanguardias, ni aún en el caso en que digan o parezcan "conducirlo". Las vanguardias que se presentan sólo como educadoras y meramente "conductoras" terminan invariablemente suplantando a sus supuestos conducidos, y convirtiendo la posible dictadura del proletariado en una dictadura burocrática de la vanguardia misma. (p. 87).

El por qué no reconocer la violencia vanguardista como violencia revolucionaria para Pérez Soto (2012) tiene un elemento evidentemente moral:

la violencia vanguardista: la facilidad con que se llega a desconocer los derechos de sus enemigos particulares. En contradicción directa con la violencia fascista, la violencia revolucionaria no tiene, ni debe tener, el contenido ni la lógica de la represalia o la venganza. Porque lo que nos interesa son cambios históricos, muy por sobre la odiosidad intersubjetiva, porque lo que nos interesa son cambios globales, muy por sobre las injusticias locales, es justo y necesario que reconozcamos a nuestros enemigos, en tanto particulares, los mismos derechos que reconocemos y reclamamos para nosotros. (p. 89).

Pérez Soto utiliza esta distinción justamente para interrogar la historia de la violencia revolucionaria, dirá que efectivamente no existe una garantía de que la violencia revolucionaria no se transforme en violencia vanguardista. Para él, esta es la diferencia radical de los marxistas de hoy con los marxistas clásicos (Pérez Soto, 2008; 2012). Lo que hace Pérez Soto es una proyección heurística de la analogía, una proyección de posibilidades nunca necesariamente probatoria, como ya se dijo. El argumento toma distancia de la sociología disciplinaria, la cual proyectaba mundos mediante la utilización de verdades científicas propio del positivismo del siglo XIX, y es justamente este espíritu el que neutraliza las instituciones y hoy se actualiza mediante la teoría de Pérez Soto. Al momento de interrogar estas líneas teóricas con el Acuerdo, es evidente que el resultado sería que dicha conclusión política se logró entre una elite alejada de los intereses populares dado su carácter vanguardista. Dicho proceso constituyente hoy no reconoce ningún proceso de participación más allá de los ejercicios de sufragio que fueron pactados la noche del 15 de noviembre, dejando la partici- 
pación política solo como un evento particular de sufragio sin iniciativas que reconozcan la participación de los territorios.

Si utilizamos algunas ideas del debate, ya que para un análisis completo se necesitaría una tesis, diremos que efectivamente lo ocurrido el 15 de noviembre fue un acuerdo entre vanguardias. El pacto político no tuvo una comprensión mediante un modo de significación imperfecta, al contrario, se utilizó un modo de significación positiva tal como se vivió en dictadura, porque se rechazó una participación amplia de todas las fuerzas políticas del sistema. El pacto se "cocinó" con la receta de una herencia institucional neoliberal, por lo que se entrega, al mismo tiempo, una expectativa de hoja en blanco, cuando en realidad la derecha pinochetista tiene la posibilidad de veto. Podríamos seguir sumando que, al final del proceso (todo esto según lo "acordado"), si no existen los 2/3 con los cuales se presentará la nueva Constitución a Chile, significaría un real proceso de crisis institucional empujado desde la elite conservadora y las vanguardias.

En este artículo, se propondrá que ambos autores, al enfrentar esta aporía política, dirán que la revolución no debe ser solamente un evento (la toma de la Bastilla o la revolución bolchevique), sino que debe tener una característica de proceso. En este sentido, sería un error pensar que tanto el Acuerdo como los plebiscitos de entrada y de salida son triunfos si no se piensan como un proceso político amplio donde se apropie el pueblo de la promesa que le fue arrebatada por el espíritu de la burguesía en la modernidad. Entre las conceptualizaciones de Atria y Pérez Soto se puede comparar que los procesos políticos deben parecerse más a una revolución de 400 años como la inglesa (Atria, 2012), esto es, una "larga marcha", diría Pérez Soto (2013, p.169), más que un evento de violencia vanguardista o infantilista como la vivida el 15 de noviembre de 2019. Entonces, si las instituciones se forman o construyen con la idea de pueblo es porque en ella existe aún una promesa que se debe hacer cumplir. En Chile, al menos esta representación ha estado en el dominio de la burguesía, la cual pacta acuerdos que evidentemente se definen con un núcleo hegemónico que expone al pueblo como parte fundamental para el funcionamiento operativo de las instituciones a una farsa; así se entiende el "Acuerdo por la paz social y la nueva Constitución". Esta tesis mira el conflicto como la oportunidad que el pueblo tuvo para hacer cumplir su promesa a la 
institucionalidad, sin embargo, esta última zafó y volvió a escribir con la mano aquello que había borrado históricamente con el codo.

Antes de continuar, es necesario aclarar que frente a un conflicto político no hay cabida para la arbitrariedad, es decir, aquel acuerdo que se pactó se debe asumir a pesar de su forma. Terminar con la Constitución de un dictador siempre será un imperativo moral democrático y, en este caso, la sociología no puede hacer relativismos intelectuales, por lo que el presente argumento se adscribe como sociología política. Para mayor claridad, es prudente reiterar que el análisis se centra en el acuerdo como evento político y las proyecciones de ese acuerdo a partir de una herencia institucional como la ya descrita. Entonces, si la experiencia nos posibilita proyectar nuevas expectativas, la prognosis política nos dice más o menos como podría devenir un futuro y cuáles son los hechos políticos de los 2/3 y la hoja en blanco. El modo de operar de la política en su consumación institucional -en este caso, como Constitución política- es cómo comienza a generar sentido de organización institucional en la voluntad del pueblo. En consecuencia, se deben pensar las instituciones desde su radicalización, dado que acabar con una Constitución liberal-autoritaria para luego empezar con una Constitución plenamente liberal no garantiza mayores derechos sociales, sino, más bien, se traduce en una nueva estrategia política de la burguesía para mantener el modelo neoliberal.

\section{Consecuencias políticas del Acuerdo por la Paz y la Nueva Constitución}

$\mathrm{Si}$ en la tesis anterior el debate busca comprender el núcleo hegemónico de la modernidad, es propio recalcar que esta aparece como consecuencia del control heredado de una clase burguesa a otra clase dominante. El canal conductor durante los últimos dos siglos fueron las instituciones de la modernidad, dado el aparato material y cultural que la convirtió en hegemonía. Si el modo de significación imperfecto tiene la razón, lo que cabría averiguar es sobre las garantías operacionales que existen en este modo de comprensión político, es decir, cuán probable es que aquello que se vuelve a prometer sea un hecho. Ese sería el problema que enfrentará la futura institucionalidad chilena y, para efectos del caso, se dirá que no hay garantías, porque no hay un control sobre el devenir del futuro ya que, como tal, este es contingente 
y más aún la institucionalidad goza de una sospecha dada su identidad hegemónica.

El proceso político que vivirá Chile dirá qué tanto se aleja del régimen neoliberal pinochetista o no. Las fuerzas políticas institucionales evidentemente mirarán con sospecha también la participación política del pueblo si este se concreta, por lo tanto, se vuelve clave para el proceso radicalizar los mecanismos de participación a nivel territorial.

Tenemos como antecedentes que desde la elite conservadora y las vanguardias políticas aparece la necesidad de dar una respuesta institucional a la revuelta popular del 18 de octubre de 2019 Dicha negociación se genera en un círculo autoconvocado por los presidentes de algunos partidos, sin pasar por el parlamento o ninguna comisión que la legislara, como ya se mencionó anteriormente. En términos generales, lo acordado fue que existirá un plebiscito de entrada y un plebiscito de salida; el proceso de construcción de una nueva Constitución será realizado con la vigencia de un texto de fondo (que no es otra cosa que la Constitución nacida en dictadura); y finalmente, dicha nueva Constitución debe ser ratificada en un próximo referéndum que dirá si hay o no una nueva Constitución.

Entonces, ¿cuándo se sabrá si efectivamente el proceso fue a partir de un acuerdo cívico y si hay una hoja en blanco o no? La respuesta se sabrá cuando se termine el proceso constituyente. Este debe convertirse en una hoja en blanco, lo cual es distinto que partir de una hoja en blanco, que es lo que se viene discutiendo desde hace algún tiempo. El proceso constituyente no comienza en una hoja en blanco, se inicia con un "texto de fondo", más $1 / 3$ de constituyentes que pueden vetar todo lo que no sea de interés para su sector. Y si se hace la pregunta: ¿por qué esto es así? La respuesta es categórica: porque así se acordó el 15 de noviembre entre la elite y las vanguardias. Esto obliga a interrogar sobre la forma en el que el proceso constituyente se llevará a cabo. Sin duda que dejar la organización de nuestras formas de vidas política, a una la elite y/o vanguardias que no tienen un modo de comprensión imperfecta, podría significar evidentemente cambiar desde una Constitución liberal-autoritaria a una liberal consolidada en democracia. Esto significa que el proceso político que vive hoy Chile es aquel momento constitucional que debe mutar desde ser un diagnóstico a revindicar procesos de participación como mecanismos de pre- 
sión de intereses para lograr una voluntad general diferente de aquella voluntad heredada desde la subsidiariedad del Estado y, de esta forma, hacer cumplir la promesa que alguna vez fue arrebatada.

\section{Conclusiones}

Este artículo no deja duda sobre cuál es la posición al plebiscito que se vivió el 25 de octubre de 2020. Rechazar esta opción de cambio constitucional evidentemente significaría una victoria rotunda para el modelo neoliberal, el cual ha resistido la evolución de la sociedad gracias a programas institucionales liberal-conservadores. El pacto del 15 de noviembre marca solamente una forma de cómo la elite logra definir las reglas con las cuales se disputa el poder, tanto así que el origen del acuerdo no garantizó escaños para pueblos originarios y tampoco una representación paritaria. Es más, esta iba hacer firmada por Sebastián Piñera, uno de los presidentes con los niveles más bajos de aprobación en encuestas de opinión pública desde que se tiene memoria. ¿Qué significaría cambiar la Constitución que nace originalmente con Augusto Pinochet por una de Sebastián Piñera dadas las condiciones análogas en la que se gesta esta salida institucional al conflicto? Es aquí cuando las instituciones funcionan como un canal conductor de la modernidad. Más allá del voluntarismo que existe desde la elite política, también se dirá que se rechaza una condición determinista de la estructura social, donde las vanguardias, aquel infantilista revolucionario o simplemente la elite son quienes siempre han antepuesto las necesidades de este núcleo hegemónico, más que un interés generalizado de la voluntad del pueblo. Por consiguiente, el análisis de este artículo fue el evento puntual del "Acuerdo por la paz y la nueva Constitución", dado que evidencia cómo los pactos se hacen a espalda del soberano, una práctica institucional con la que ya nos tiene acostumbrados la institucionalidad política chilena.

Una nueva institucionalidad que se cargue de un contenido esperanzador o emancipador, pero que, al mismo tiempo, vuelva a incumplir su promesa significaría también otro triunfo del modelo, dado que es aquí donde liberales-conservadores definen su carácter de hegemonía, es decir, en la medida en que existe un fracaso colectivo, tal como lo vivió la modernidad, es cuando comienzan aparecer las desafecciones con la esfera pública. Durante los últimos años hemos visto una 
baja percepción de la democracia como régimen de gobernabilidad en Latinoamérica. Los acuerdos políticos buscan la representación de intereses desde las partes. Cuando no se asegura que el solo equilibrio favorece al total de las clases sociales, se genera una percepción de una mala distribución de justicia (Peña, 2020) tal como se vive hoy.

Este artículo nunca tuvo la pretensión de generar una descripción de la protesta, tal como lo vienen haciendo las teorías de los movimientos sociales o novísimos movimientos sociales, si se prefiere; tampoco quiso ser una "receta" desde las ciencias políticas, y mucho menos desde las ciencias jurídicas; no se buscó un ejercicio diplomático de sugerencias sobre cómo debiese la institucionalidad escribir la hoja en blanco; es más bien un análisis que comprende la relación entre los enlaces sociales como emergencia entre la agencia y la estructura (Mascareño, 2008), y cómo desde aquí no se puede hacer solamente una comprensión probabilística de la institucionalidad, sino también observar cuál es la mejor manera de dirigir el modo de significación imperfecta de la cuestión propiamente política y de esta manera aislar lo que hemos denominado una lectura moderna de la sociedad, esto es sociología política. Desde la teoría, sí es posible construir aparatos de análisis y adscribir a programas políticos que tengan como pretensión la radicalización de las instituciones democráticas con el fin de romper con tradiciones modernas.

Aún así, frente a un contexto de crisis institucional, es claro que las ciencias sociales, en especial la sociología, ya saben (más o menos) cuál es el diagnostico. Frente a esto, la comunidad política o el pueblo no puede ser neutralizado mediante nuevos relativismos ni científicos, ni mucho menos filosóficos.

Para concluir se dirá que en el movimiento pendular del tiempo subyace la cuestión más enraizada de la teoría social moderna. Liberales-conservadores lo entienden así y es por eso que hoy,mediante la fuerza de la globalización, se puede decir que se vive bajo el dominio de democracias liberales o ideas muertas. En ellas existe un programa hegemonizado que cancela la participación amplia de la democracia como un mecanismo de representación del pueblo, más allá de la discusión de si las democracias representativas o participativas son regímenes que responden a intereses de clase. Lo prudente será decir que nuestras expectativas, más que ser construidas por aparatos científi- 
cos, deben estar sujetas a la existencia (dada su condición de posibilidad) de una institución radicalmente democrática, en comparación a cómo se ha desarrollado la cultura política chilena, la cual ha sido concebida mediante una contradicción de nuestras formas de vida 0 , en términos atrianos, mediante una experiencia existencial en déficit. Si los referentes históricos que se construyen desde la experiencia nos proyectan a una posibilidad de futuro y, por ende, de expectativas, entonces es cierto decir que, frente al dominio neoliberal, más vale ser realistas y pedir lo imposible: asamblea constituyente ahora.

\section{Referencias}

Acuerdo por la paz social y la nueva Constitución. (15 de noviembre de 2019). Biblioteca Nacional del Congreso de Chile. Recuperado de https://obtienearchivo.bcn.cl/obtienearchivo?id=doc umentos/10221.1/76280/1/Acuerdo_por_la_Paz.pdf

Archer, M. (Introducción del traductor de Chernilo, D.). (2009). Teoría social realista: el enfoque morfogenético. Santiago de Chile: Editorial Universidad Alberto Hurtado.

Atria, F. (2009). Viviendo bajo ideas muertas: la ley y la voluntad del pueblo. Trabajo presentado en el IV Congreso estudiantil de teoría del derecho constitucional, Universidad de Chile, Santiago de Chile.

Atria, F. (2012). La idea de teología política. Derecho y Humanidades, (20), 93-125. Recuperado de https://derechoyhumanidades. uchile.cl/index.php/RDH/article/view/34817/36520

Atria, F. (2013). La Constitución tramposa. Santiago de Chile: LOM Ediciones.

Barboza, A. (2006) Sobre el método de la interpretación documental y el uso de las imágenes en sociología: Karl Mannheim, Aby Warburg y Pierre Bourdieu. Sociedade e Estado, 21(2), 391414. doi: 10.1590/S0102-69922006000200005

Chernilo, D. \& Mascareño, A. (2010). Obstáculos y perspectivas de la sociología latinoamericana. Universalismo normativo y diferenciación funcional. En A. Mascareño (Ed.), Diferenciación y contingencia en América Latina. Santiago de Chile: Ediciones Universidad Alberto Hurtado.

Farías Carrión, E. (diciembre, 2019). Hacia un nuevo horizonte de sentido histórico de una civilización de vida. Teoría social: La 
instauración de la ideología (neo)liberal y la respuesta de la sociología. Trabajo presentado en el Congreso ALAS, Perú.

Farías Carrión, E. \& Moreno Figueras, J. J. (2016). Estado subsidiario: límites y proyecciones de la democracia territorial en Chile. Revista Temas Sociológicos, (19), 105-132. doi: 10.29344/07196458.19.264

Koselleck, R. (2003). Aceleración, prognosis y secularización. Valencia: Pre-textos.

Marx, K. (2009). El 18 brumario de Luis Bonaparte. Madrid: Fundación Federico Engels.

Mascareño, A. (2008). Acción, estructura y emergencia en la teoría sociológica. Revista de Sociología, (22), 217-256. doi: 10.5354/0719-529X.2008.14492

Mascareño, A. (2010). Diferenciación y contingencia en América Latina. Santiago de Chile: Ediciones Universidad Alberto Hurtado.

Mayol, A. (2012). El derrumbe del modelo. La crisis de la economía de mercado en el Chile contemporáneo. Santiago de Chile: LOM Ediciones.

Moulian, T. (2002). Chile actual. Anatomía de un mito. Santiago de Chile: LOM Ediciones.

Oficina del Alto Comisionado de las Naciones Unidas para los Derechos Humanos. (15 de diciembre de 2019). Informe de la Oficina de Derechos Humanos de la ONU sobre la crisis en Chile describe múltiples violaciones de derechos humanos de Carabineros y hace un llamado a reformas. Oficina del Alto Comisionado de las Naciones Unidas para los Derechos Humanos. Recuperado el 19 de noviembre de 2020, de https://www.ohchr.org/SP/NewsEvents/Pages/DisplayNews.aspx?NewsID $=25423 \&$ LangID $=\mathrm{S}$

Ortega, E. (1992). Historia de una alianza. Santiago de Chile: LOM Ediciones.

Peña, C. (2020). La revolución inhallable. Estudios Públicos, (158), 7-29. doi: 10.38178/07161115/2020.001

Pérez Soto, C. (2008). Para una crítica del poder burocrático: comunistas otra vez. Santiago de Chile: LOM Ediciones.

Pérez Soto, C. (2012). La violencia del derecho y derecho a la violencia. Derecho y Humanidades, (20), 73-91. doi: 10.5354/07192517.2014.34816 
Pérez Soto, C. (2008). Proposición de un marxismo hegeliano. Santiago de Chile: editorial ARCIS.

Ruiz, C. (2019). La política en el neoliberalismo. Experiencias latinoamericanas. Santiago de Chile: LOM Ediciones.

Rojas, L. (2011). De la rebelión popular a la sublevación imaginada. Antecedentes de la historia política y militar del partido comunista de Chile y el FPMR 1973-1990. Santiago de Chile: LOM Ediciones.

Saleh, F. (1 de junio de 2017). Andrés Zaldívar, de honorable maestro de "cocina" a anfitrión de la última cuenta pública de Bachelet. El Mostrador. Recuperado el 19 de noviembre de 2020, de https://www.elmostrador.cl/noticias/pais/2017/06/01/ andres-zaldivar-de-honorable-maestro-de-cocina-a-anfitrion-de-la-ultima-cuenta-publica-de-bachelet/

Tagle, M. (Ed.). (1995). El acuerdo nacional: Significados y perspectivas (Vol. 3, Diálogos). Santiago de Chile: Corporación Justicia y Democracia. Recuperado de http://www.memoriachilena. gob.cl/archivos2/pdfs/MC0053699.pdf 